\title{
Contrasting effects of age of acquisition and word frequency on auditory and visual lexical decision
}

\author{
JUDITH E. TURNER \\ University of Reading, Reading, England \\ TIM VALENTINE \\ Goldsmiths College, University of London, London, England \\ and \\ ANDREW W. ELLIS \\ University of York, York, England
}

\begin{abstract}
In four experiments, we examined the effects of frequency and age of acquisition on auditory and visual lexical decision. Word frequency affected visual, but not auditory, lexical decision speed (Experiments 1 and 3). Age of acquisition affected lexical decision speed in both modalities (Experiments 2 and 4). We suggest that previous reports of effects of frequency on auditory lexical decision may be due to a confounding of frequency with age of acquisition, and we discuss the implications of these findings for theories of auditory and visual word recognition.
\end{abstract}

Some words are recognized, comprehended, or produced more rapidly than others. Much theoretical and empirical work has gone into trying to determine just what the effective variables in lexical processing are and how their influence should be explained.

One property of words that is widely held to influence lexical processing is the frequency with which they occur within the language (Monsell, 1991). Frequency effects have been reported in a wide variety of word recognition and production tasks. One such is the task of naming pictures of objects. Oldfield and Wingfield (1965) reported a significant correlation between the speed of object naming and the frequency with which those names occur in the language, and there have been several reports since of effects of word frequency on object naming (e.g., Jescheniak \& Levelt, 1994). Similarly, there have been many reports of effects of frequency on the speed with which written words can be read aloud (e.g., Connine, Mullinex, Shernoff, \& Yelen, 1990; Monsell, Doyle, \& Haggard, 1989).

Other studies have, however, questioned whether the effects attributed to frequency in object and word naming might not be due, at least in part, to a different, but

This research was supported by a grant from the Medical Research Council of the United Kingdom (G9420459N). We thank Catriona Morrison and Tameron Chappell for constructive help with the early stages of this project. We are grateful to Steven Roodenrys for supplying us with a program for computing phonological neighbors. Correspondence concerning this article should be addressed to J. E. Turner, Department of Psychology, University of Reading, 3 Earley Gate, Whiteknights, P.O. Box 238, Reading RG6 6AL, England (e-mail: j.e.turner@reading.ac.uk).

-Accepted by previous associate editor Kathryn T. Spoehr related, variable: age of acquisition. The proposal here is that the age at which words are learned (or, perhaps, the order in which they are learned) influences the speed and accuracy with which they can be recognized in adulthood, with words learned early being processed more rapidly and more accurately than words acquired later. Frequency and age of acquisition are clearly related: the words that children learn earliest in life tend to be the words that occur with high frequency in adults' language. Age of acquisition correlates highly with frequency, with the degree of correlation depending on the precise sample of words selected. It is, however, possible to distinguish frequency and age of acquisition conceptually as well as empirically. For example, some of the words that children learn early occur predominantly in stories and have a low frequency in adult discourse (e.g., elephant, dragon, castle). There are also words that are acquired relatively late but that are of high written or spoken frequency among adults (e.g., student, committee, subject).

Carroll and White (1973a, 1973b) reported that objectnaming speed was predicted better by estimates of age of acquisition than by word frequency, and that when the two variables were entered together into a regression analysis, only the contribution of age of acquisition was significant. Gilhooly and Gilhooly (1979), Morrison, Ellis, and Quinlan (1992), and Barry, Morrison, and Ellis (1997) reported similar findings, and Morrison et al. (1992) showed that age of acquisition predicted naming speed better than did word frequency for the original Oldfield and Wingfield (1965) data.

Regression studies have also been unanimous in reporting effects of age of acquisition but not word frequency on the speed of reading words aloud (Brown \& Watson, 1987; Gilhooly \& Logie, 1981; Rubin, 1980). Using a fac- 
torial rather than a correlational method, Morrison and Ellis (1995) found no effect of frequency on word naming when age of acquisition was controlled, but a strong effect of age of acquisition when frequency was controlled.

Belief in the reality of frequency effects is, however, hard to shake. Theoretical models of word recognition and production have typically been designed around the idea that the more frequently a word is encountered, the more rapidly or accurately it will be recognized. For example, in Morton's $(1969,1979)$ logogen model, individual logogens (word detectors) have frequency-dependent thresholds for word detection. In Marslen-Wilson's (1987) cohort model, responses to higher frequency word forms are enhanced so that the levels of activation of these elements rise more rapidly, while in Luce's (1986) neighborhood activation model, decision units are biased by word frequency. Connectionist models of word recognition also assign a central role to word frequency. For example, McClelland and Rumelhart's (1981) interactive activation model of word recognition has frequencydependent baseline activation levels, while in distributed memory models such as that of Seidenberg and McClelland (1989), the strength of connections between representations is a function of the frequency with which different words are encountered. Most current models of lexical processing would be severely compromised if it was established convincingly that word frequency did not affect some aspects of word recognition (Monsell, 1991).

In contrast, age of acquisition has received little theoretical attention, and there have been few attempts to explain the mechanism by which that variable may exert its effects. Age of acquisition is known to affect objectnaming speed, but not the speed with which pictures of objects can be classified into semantic categories (Morrison et al., 1992). Naming of words following a delayed cue is also unaffected by age of acquisition (Morrison \& Ellis, 1995), so the effect does not seem to lie within the process of articulation itself. Finally, age of acquisition does not affect accuracy in episodic memory tasks (V. Coltheart \& Winograd, 1986; Gilhooly \& Gilhooly, 1979; Rubin, 1980). Most theorists have concluded, therefore, that age of acquisition affects the speed with which lexical representations of words can be accessed and retrieved. Gilhooly and Watson (1981) suggested that the influence of age of acquisition may occur at the level of "speech output logogens" in the revised logogen model (Morton, 1979). They proposed that speech output logogens for early acquired words might have lower activation thresholds than logogens for later acquired words. Brown and Watson (1987) suggested that the phonological output representations for early acquired words are more complete than those for later acquired words and can therefore be accessed more readily.

As we have indicated, research aimed at trying to disentangle the influences of age of acquisition and word frequency has mostly concentrated on object naming and word naming. In the present paper, we are primarily concerned with the relative contributions of age of acquisi- tion and frequency to the recognition of spoken words. High-frequency words have been reported to be more intelligible when heard in white noise than words of lower frequency (Broadbent, 1967; Howes, 1957). Using the phoneme monitoring task, Dupoix and Mehler (1990) reported that initial phonemes were detected faster in highthan in low-frequency words when the stimuli were monosyllabic words, though not when the stimuli were disyllabic words. Tyler (1984) examined frequency effects in the gating paradigm in which subjects are presented with fragments of words of increasing duration until they identify the word accurately. Tyler found frequency effects that were restricted to stimuli that could be identified from relatively short initial segments ("gates" of $200 \mathrm{msec}$ or less).

Frequency effects have also been reported in auditory lexical decision, where subjects must decide as quickly as possible whether spoken stimuli are words or nonwords (Blosfeld \& Bradley, 1981; Dupoix \& Mehler, 1990; Marslen-Wilson, 1987; McCusker, Hillinger, \& Bias, 1981). Age of acquisition was not controlled in any of those studies, and the possibility that part or all of the apparent frequency effects might have been effects of age of acquisition must be taken seriously. However, Cirrin (1984) reported that both age of acquisition and frequency affected auditory decision speed in adults and first-grade children. A similar pattern of independent contributions of both frequency and age of acquisition has been found in the visual lexical decision task, where written words must be distinguished from nonwords (Butler \& Haines, 1979; Morrison \& Ellis, 1995; Nagy, Anderson, Schommer, Scott, \& Stallman, 1989).

Cirrin (1984) is one of the very few to have looked for effects of age of acquisition in auditory word recognition. Young and Ellis (1980) required subjects to identify early and late acquired nouns presented in noise. They found that early acquired words were recognized more accurately than late acquired words when the words were matched on frequency, imageability, concreteness, familiarity, and letter length. They did not examine the effect of frequency on the identification of words matched on age of acquisition or other factors (though we have noted Broadbent's [1967] and Howes's [1957] reports of frequency effects on the recognition of words presented in noise using lists uncontrolled for age of acquisition). Gilhooly and Logie (1981) presented spoken words at low volumes. A multiple regression analysis produced an effect of frequency but not age of acquisition on word recognition accuracy.

In the present experiments, we looked at the effects of frequency on auditory lexical decision (Experiment 1) and written lexical decision (Experiment 3 ), using sets of words matched on age of acquisition and other variables, and at the effects of age of acquisition on auditory lexical decision (Experiment 2) and written lexical decision (Experiment 4), using sets of words matched on frequency and other factors. The measurement of auditory lexical decision speed is complicated by the fact that 
spoken words are not presented instantaneously like written words but are spread over time. Sets of high- and low-frequency words, or early and late acquired words, must be matched on the point at which they can be unambiguously identified, and matched on the point from which the reaction time is measured. Marslen-Wilson (1987) compared auditory lexical decision speeds for sets of high- and low-frequency words. The sets were made up of pairs of words that differed only on their final phonemes (e.g., street/streak). Selecting pairs of words in this way guarantees that the sets are matched on uniqueness point (the point in the word at which it can be distinguished from all other words) and cohort size (the number of words sharing the same initial phonemes). We adopted the same matching technique for the present experiments. Because the same word sets were used in Experiments 1 and 3, and in Experiments 2 and 4, and because they were matched on the same variables, we shall describe the selection of the materials first and then report the experiments in which they were used.

\section{EXPERIMENT 1}

Experiment 1 was designed to examine the effect of frequency on auditory lexical decision when age of acquisition is controlled. Subjects made lexical decisions to high- and low-frequency words that were interspersed among equal numbers of nonwords. Words were matched for age of acquisition, imageability, length, phoneme type, and uniqueness point.

\section{Method}

Subjects. The subjects for all experiments were volunteer undergraduates or postgraduates from the University of Durham. All had normal hearing and were paid for their participation. Twenty subjects took part in Experiment 1.

Materials. The stimuli consisted of 32 pairs of monosyllabic words of either 3 or 4 phonemes (mean length $=3.16$; standard deviation $=0.37$ ). The words of each pair were identical except for one phoneme (the final consonants in 30 pairs and the medial vowels in 2 pairs). The uniqueness point (the point at which a spoken item can be distinguished from all other items of the language) in all items was the final phoneme, and the sets were matched for phoneme length.

One word in each pair was of higher frequency and one of lower frequency (referred to henceforth as high and low frequency). Two measures of frequency were used. Frequency counts based on written American English were taken from Francis and Kučera (1982), whereas contemporary British spoken word frequency was taken from the CELEX database (Centre for Lexical Information, 1993). The mean occurrence per million for the higher frequency words was 182 for written American English and 217 for spoken British English. For the lower frequency words, the mean occurrence per million was 19 for written American English and 10 for spoken British English. This is in the range of differences that has been found to produce (apparent) frequency effects in word recognition.

The high- and low-frequency word sets were matched on age of acquisition and imageability taken from the MRC/Oxford Psycholinguistic Database (Quinlan, 1992). Age of acquisition is rated on a scale from 1 to 7 , where $1=$ learned before the age of 3 and 7 = learned at age 13 or over (Gilhooly \& Logie. 1980). Such estimates have been shown to be reliable (Gilhooly \& Watson, 1981) and to correlate highly with objective measures of word learning age in children (Carroll \& White, 1973a; Gilhooly \& Gilhooly, 1980; Morrison, Chappell, \& Ellis, 1997). Imageability ratings are based on the ease with which a word arouses a mental image. They were also generated using a 7-point scale (from Paivio, Yuille, \& Madigan, 1968).

The word sets were also matched for their orthographic and phonological neighborhood sizes (i.e., the number of other words that can be generated by changing a single letter or sound in a word). Reaction times are generally shorter for words that have more neighbors (see, e.g., Sears, Hino, \& Lupker, 1995). Orthographic neighborhood sizes were calculated using the $N$ measure of M. Coltheart, Davelaar, Jonasson, and Besner (1977) and were found not to differ significantly for high- and low-frequency word sets $(t=0.84, p>05)$. Phonological neighbors were calculated in a similar fashion, but on the basis of phoneme changes rather than letter changes, using a program devised by $\mathrm{S}$. Roodenrys. The use of phonologically similar pairs minimizes the differences between the word sets in the number of phonological neighbors, and again the difference was not significant $(t=0.52, p>.05)$. Sixty-one percent of the words ended in a stop consonant. The word sets used in Experiment 1 are shown in Appendix A.

Spoken nonwords were created by changing the final phonemes of a set of 66 words, which were matched to the target words on length. The resulting items were easily pronounceable and wordlike. Devising the nonwords in this way meant that the stimuli could not be categorized as words or nonwords until the final phoneme had been identified. For written presentation, the nonwords were spelled using standard English phoneme-grapheme correspondences. Examples are wret, bipe, vome, denk, brif, and mup.

Procedure. The experiment was carried out using a Power Macintosh $7100 / 80 \mathrm{AV}$ computer. Items were recorded on DAT tapes in a sound-attenuating chamber and were stored by the computer at a $20-\mathrm{kHz}$ sampling rate, using the program SoundEdit 16 . Items were output in the required order and reaction times were measured using the program SuperLab 1.68. The subjects were tested individually. The stimuli were presented via headphones. A warning tone occurred $500 \mathrm{msec}$ before the presentation of each item. The subjects were required to decide as rapidly as possible whether each item was a word or a nonword. Responses were made by pressing a key. The "word" response was made with the right hand. The subjects were given a series of 20 practice trials at the outset to familiarize them with the task. The experimental stimuli were then presented in two blocks. Each block contained 16 high-frequency words, 16 low-frequency words, and 32 nonwords. The order of presentation of the items was randomized for each subject.

Data analysis. Reaction time was measured from the offset of the spoken word to the keypress. Offset was measured from the earliest point at which the final phoneme of each word could be identified. Sixty-one percent of the words had stop consonants for their final phoneme, for which this offset is readily apparent in a waveform representation of the word. Two trained listeners measured the length of these items: the mean was used in calculations (correlation between the two sets of measurements $=.99$; mean difference $=$ $9 \mathrm{msec}$ ). Stop consonants occurred approximately equally as final phonemes in the higher and lower frequency condition. For the remaining 25 items, the minimum length required for identification of the final phoneme was measured by a group of six trained listeners. The mean of the four closest measurements was used as the measure of word length. The mean difference between the longest and shortest of these measurements was $22 \mathrm{msec}$ (median $=20 \mathrm{msec}$; standard deviation $=12 \mathrm{msec}$ ).

\section{Results}

Only responses to real words were analyzed. There were 88 false negative responses to words ( 30 to high-frequency words; 58 to low-frequency words). The tendency for subjects to make more false negative responses to low- 
than to high-frequency words was significant by subjects (Wilcoxon matched pairs signed ranks test: $z=-2.72$, $p<.01)$ but not by items $(z=-0.80$, n.s. $)$.

For the by-subjects analysis, each subject's mean reaction time was calculated and any reaction times falling more than 2.5 standard deviations from the mean were removed. This procedure resulted in a further 27 responses' being removed and a total of $9 \%$ of responses being excluded from the data. High-frequency items accounted for $52 \%$ of the total removals; low-frequency, for $48 \%$.

The resulting mean reaction times (by subjects) were $576 \mathrm{msec}$ (standard deviation $=91.7$ ) for the highfrequency items and $568 \mathrm{msec}$ (standard deviation = 74.6) for the low-frequency items. The difference of $8 \mathrm{msec}$ in favor of low-frequency words was not significant $[t(19)=0.83, p=.41]$.

The same procedure was adopted for a by-items analysis. Twenty-three responses that fell more than 2.5 standard deviations from each item's mean were removed from the analysis. High-frequency items accounted for $38 \%$ of the total removals. The means were recalculated (high frequency $=577 \mathrm{msec}$, standard deviation $=84.0$; low frequency $=571 \mathrm{msec}$, standard deviation $=88.5$ ). A $t$ test again showed that the difference in reaction times was not significant by items $[t(31)=.06, p=.95]$.

\section{Discussion}

There was a tendency in Experiment 1 for subjects to misclassify more low- than high-frequency words as nonwords, but the difference was only significant in the by-subjects analysis, suggesting that the effect was due to a minority of items. Auditory lexical decision speed did not differ for high- and low-frequency words matched on age of acquisition: Indeed the nonsignificant trend was toward faster responses to the low-frequency words. This result fails to replicate Cirrin's (1984) report of independent effects of frequency and age of acquisition on auditory lexical decision speed, obtained using a multiple regression analysis.

Experiment 1 raises the possibility that previously reported effects of frequency on auditory lexical decision speed without control for age of acquisition may have been effects of age of acquisition rather than effects of frequency (see Blosfeld \& Bradley, 1981; Dupoix \& Mehler, 1990; Marslen-Wilson, 1987; McCusker et al., 1981). For this argument to be sustained, it is first necessary to show that age of acquisition does indeed affect auditory lexical decision speed.

\section{EXPERIMENT 2}

In Experiment 2, we examined the effect of age of acquisition on auditory lexical decision, using word sets matched for frequency, imageability, length, cohort size, and position of the uniqueness point.

\section{Method}

Subjects. Twenty subjects took part in this experiment.

Materials and Procedure. The stimuli for Experiment 2 consisted of 33 pairs of monosyllabic words 3 or 4 phonemes long (mean length $=3.2$ phonemes; standard deviation $=0.42$ ). The words of a pair differed by a single phoneme (the final consonants differed in 30 pairs, and the medial vowels, in three pairs). One member of each word pair was of earlier age of acquisition and one of later age of acquisition (henceforth early and late). The mean for the early age of acquisition words was 2.4 , and for the later acquired words, 3.5. The difference of 1.1 on the 7-point age of acquisition scale represents between 2 and 3 years difference in the estimated age at which the items were first learned. The early and late acquired word sets were also matched on frequency (both spoken and written), imageability, length, and uniqueness point. The number of orthographic and phonological neighbors did not differ significantly [orthographic, $t(32)=1.43, p>.05$; phonological, $t(32)=0.22$, $p>.05]$. Fifty-eight percent of the words ended in stop consonants. The word sets are shown in Appendix B. Other aspects of the procedure and data analysis were the same as in Experiment 1.

\section{Results}

Only responses to real words were analyzed. There were 67 false negative responses to words ( 10 to early acquired words; 57 to late acquired words). The difference in false positive error rate in responses to early and late acquired words was significant both by subjects $(z=$ $-3.62, p<.01)$ and by items $(z=-3.30, p<.01)$.

A by-subjects analysis was performed in the same way as for Experiment 1, and 30 more responses were removed. The overall removal rate was $7 \%$. Fifty-seven percent of the responses removed from the analysis were made to late acquired items. The mean reaction times were $558 \mathrm{msec}$ for early acquired words (standard deviation $=100.1$ ) and $604 \mathrm{msec}$ for late acquired words (standard deviation $=104.9$ ). This difference was highly significant $[t(19)=5.8, p<.0001]$.

Thirty-seven items were removed from the data prior to analysis by items. Altogether, $8 \%$ of items were not included in the analysis. Fifty-seven percent of the errors and slow responses were made to late acquired items. Mean reaction times were $555 \mathrm{msec}$ (standard deviation $=64.2$ ) for the early acquired items and $605 \mathrm{msec}$ (standard deviation $=77.1$ ) for the late acquired items. The by-items $t$ test was also significant $[t(32)=2.3, p<.05]$.

\section{Discussion}

In Experiment 1, no effect of word frequency on auditory lexical decision speed was found once age of acquisition was controlled. In contrast, in Experiment 2 there was a strong effect of age of acquisition on auditory lexical decision speed using word sets matched for frequency (see Cirrin, 1984). There were also more false negative errors to late than to early acquired words.

The finding of a strong effect of age of acquisition on auditory lexical decision speed reinforces the suggestion that previously reported effects of frequency on auditory word recognition may, in fact, have been due to the uncontrolled effects of age of acquisition. We noted in the 
introduction, though, that several previous studies have yielded independent effects of both frequency and age of acquisition on visual lexical decision speed (Butler \& Hains, 1979; Morrison \& Ellis, 1995; Nagy et al., 1989; Whaley, 1978). This raises the possibility that whereas age of acquisition may affect both visual and auditory lexical decision speed, word frequency may affect visual but not auditory lexical decision. In Experiments 3 and 4 , we used the same word sets that had yielded an age of acquisition effect but no frequency effect in Experiments 1 and 2 , but this time in visual rather than auditory lexical decision.

\section{EXPERIMENT 3}

In Experiment 3, we examined the effect of frequency on lexical decision in the visual modality with age of acquisition controlled, using the same word sets as in Experiment 1.

\begin{abstract}
Method
Subjects. Twenty-six subjects took part in Experiment 3.

Design and Procedure. The same sets of words were used as in Experiment 1 (see Appendix A). The stimuli were presented visually using SuperLab software. Words appeared centrally on the screen in lowercase bold 12-point Geneva font. Each stimulus item was preceded by a fixation point, which was replaced by the stimulus item after $200 \mathrm{msec}$. There was a $500-\mathrm{msec}$ delay between the subject's response and the onset of the next trial. Nonwords were appropriate spellings of the auditory nonwords used in Experiment $l$ and were matched to the words for letter length. The subjects sat at a comfortable viewing distance from the screen (approximately $60 \mathrm{~cm}$ ). Reaction times were measured from the onset of each word. Other aspects of procedure and data analysis were the same as in Experiment 1.
\end{abstract}

\section{Results}

There were 73 false negative responses to words ( 58 to low-frequency words; 30 to high-frequency words). The difference in the rate of false negative errors to high- and low-frequency words was significant both by subjects $(z=-2.24, p<.05)$ and by items $(z=-2.78, p<.01)$.

For the by-subjects analysis, a further 45 items whose reaction times fell more than 2.5 standard deviations from the mean were removed from the analysis. The overall number of items eliminated from analysis was $7 \%$. High-frequency items accounted for $38 \%$ of the removals.

The by-subjects analysis was performed in the same way as for Experiment 1. The mean reaction times were $553 \mathrm{msec}$ for high-frequency words (standard deviation = 51.3 ) and $586 \mathrm{msec}$ for low-frequency words (standard deviation $=59.0$ ). This difference of $33 \mathrm{msec}$ was significant $[t(25)=5.2, p<.0001]$.

The by-items analysis led to the removal of 39 items. The overall removal rate was $7 \%$, and $38 \%$ of the errors were for high-frequency items. Mean reaction times were $551 \mathrm{msec}$ (standard deviation $=40.5$ ) for high-frequency items and $583 \mathrm{msec}$ (standard deviation $=27.1$ ) for low- frequency items. The by-items $t$ test was also significant $[t(31)=4.8, p<.0001]$.

\section{Discussion}

The same word sets that yielded a nonsignificant advantage for low-frequency words in Experiment 1 (auditory lexical decision) generated a highly significant 33msec reaction time difference in favor of high-frequency words in Experiment 3 (visual lexical decision). This result is consistent with previous reports of frequency effects in visual lexical decision, even when age of acquisition is controlled (Butler \& Hains, 1979; Morrison \& Ellis, 1995; Nagy et al., 1989; Whaley, 1978). There were also significantly more false negative errors to low-than to high-frequency words.

The overall reaction times in Experiments 1 and 3 were very similar, so the difference in outcome between the two experiments cannot be attributed to lexical decision speeds' being faster in one task than in the other. The fact that a significant frequency effect emerged in Experiment 3 also shows that the word sets were capable of detecting frequency effects where such effects were to be had. The results of Experiments $l$ and 3 indicate that word frequency has a genuine effect on visual lexical decision speed, but not on auditory lexical decision speed.

\section{EXPERIMENT 4}

In Experiment 4, we examined the effect of age of acquisition on visual lexical decision, using the same word sets that were employed in Experiment 2.

\section{Method}

Subjects. Twenty-five subjects took part in Experiment 4.

Design and Procedure. The word sets used in Experiment 4 were the same as in Experiment 2 (see Appendix B). The procedure and data analysis were the same as in Experiment 3.

\section{Results}

There were 89 false negative responses to words ( 27 to early acquired words; 62 to late acquired words). The difference in false positive error rate to early and late acquired words was significant both by subjects $(z=-2.68$, $p<.01)$ and by items $(z=-2.21, p<.05)$.

A by-subjects analysis was performed as in Experiment 1 , which led to the removal of a further 16 responses that fell more than 2.5 standard deviations outside the mean reaction time. The overall removal rate was $6 \%$. Late acquired words accounted for $67 \%$ of the total removals. Mean reaction times were $600 \mathrm{msec}$ for the early acquired words (standard deviation $=103.2$ ) and $625 \mathrm{msec}$ for the late acquired words (standard deviation $=118.2$ ). This difference of $25 \mathrm{msec}$ was significant $[t(24)=2.9, p<.01]$.

The by-items analysis resulted in the removal of an additional 45 items. The overall error rate was $8 \%$. Late acquired words accounted for $61 \%$ of the errors. The mean 
reaction times were $586 \mathrm{msec}$ for the early acquired words (standard deviation $=73.2$ ) and $626 \mathrm{msec}$ for the late acquired words ( standard deviation $=35.2$ ). This difference of $40 \mathrm{msec}$ was also significant $[t(32)=2.8, p<.01]$.

\section{Discussion}

Late acquired words attracted more errors than did early acquired words in Experiment 4, and visual lexical decision responses were made more rapidly if the stimulus word had an early age of acquisition. This result replicates the findings of Butler and Hains (1979), Morrison and Ellis (1995), Nagy et al. (1989), and Whaley (1978).

\section{GENERAL DISCUSSION}

In the present experiments, we found effects of age of acquisition on both auditory lexical decision speed (Experiment 2) and visual lexical decision speed (Experiment 4), with early learned words being responded to faster than later learned words in both cases. These results were obtained with the use of word sets matched on frequency as well as on imageability, length, cohort size, and position of the uniqueness point. ${ }^{1}$

The finding of an effect of age of acquisition on auditory lexical decision speed is in line with Cirrin's (1984) results, while the effect of age of acquisition on visual lexical decision speed replicates the findings of Butler and Hains (1979), Morrison and Ellis (1995), Nagy et al. (1989), and Whaley (1978). Strong effects of age of acquisition have also been reported on object naming speed (Barry et al., 1997; Carroll \& White, 1973a, 1973b; Gilhooly \& Gilhooly, 1979; Morrison et al., 1992) and word naming speed (Brown \& Watson, 1987; Gilhooly \& Logie, 1981; Morrison \& Ellis, 1995; Rubin, 1980). Taken together, these results show that the age at which a word is learned, or perhaps the order in which words are learned, is a powerful determinant of the speed with which lexical representations can be accessed and retrieved in adulthood.

In Experiment 3, we found a significant effect of word frequency on visual lexical decision speed, using sets of words matched on frequency and other factors. Experiments 3 and $\mathbf{4}$ together suggest that visual lexical decision speed is affected by both age of acquisition and word frequency, a pattern of results that has emerged from other studies of visual lexical decision speed (Butler \& Hains, 1979; Morrison \& Ellis, 1995; Nagy et al., 1989; Whaley, 1978). The robust effect of word frequency on visual lexical decision speed contrasts with the situation in word naming (reading aloud), where frequency effects have proved hard to find once age of acquisition is controlled (Brown \& Watson, 1987; Gilhooly \& Logie, 1981; Rubin, 1980). Morrison and Ellis (1995) found an effect of frequency on visual lexical decision but not word naming, using word sets matched on age of acquisition. They noted that if word frequency affects the speed with which orthographic representations can be accessed, as has often been proposed, then frequency should affect both word naming and visual lexical decision. If, however, frequency has much more of an effect on visual lexical decision speed than on word naming, its influence must be upon some postlexical process that is involved in the deciding of whether or not a string of letters is a word, but is not involved in the reading of that letter string aloud. The possibility of a postlexical contribution of frequency to visual lexical decision has been discussed by Balota and Chumbley (1984) and Morton (1982), among others.

Whatever postlexical, frequency-sensitive process is involved in one's deciding whether a written letter string is a word or not does not seem to be involved in one's deciding whether a string of speech sounds is or is not a word. In Experiment 1, we found no trace of an effect of frequency on auditory lexical decision speed (using the same word sets that yielded a highly significant effect in Experiment 3 with similar overall reaction times). Combined with the growing list of studies reporting little or no effect of word frequency on object or word naming speed once age of acquisition is controlled, this result casts severe doubt on the long-assumed importance of frequency as a determinant of the speed of accessing lexical representations. We suggest that previous reports of "frequency" effects in auditory lexical decision (Blosfeld \& Bradley, 1981; Dupoix \& Mehler, 1990; MarslenWilson, 1987; McCusker et al., 1981) may have arisen because of a failure to control for age of acquisition when selecting sets of high- and low-frequency items. When that happens, frequency and age of acquisition are always seriously confounded (see Morrison \& Ellis, 1995, Table 1). Part or all of the "frequency" effect reported in other auditory word recognition tasks such as the phoneme monitoring task (Dupoix \& Mehler, 1990) and the gating task (Tyler, 1984) may also be due to age of acquisition, though we note that in Experiment 1 there was a tendency for there to be more false negative responses to low- than to high-frequency words that was significant by subjects though not by items.

Few contemporary models of word recognition and production posit a single "mental lexicon": Most propose a separation at least between phonological representations involved in recognizing and producing spoken words on the one hand, and orthographic representations involved in recognizing and producing written words on the other. Some go further and propose a further distinction between the lexical representations involved in recognition and those involved in production. If the existence of two or more lexicons is granted, the question arises whether age of acquisition affects some or all of these lexical stores, and whether the same precise version of age of acquisition is involved in every case.

Much vocabulary acquisition occurs in early childhood, but words continue to be learned throughout childhood and adulthood. The acquisition of written word forms begins later than the acquisition of spoken word 
forms and may be spread out more over late childhood. We have mentioned earlier Morrison and Ellis's (1995) suggestion that a growing mental lexicon may be likened to a neural network that is required to learn and retain an ever expanding set of items. This is unlike the situation typically employed in the training of connectionist models of word recognition or production, in which all of the items in the training set are introduced at the outset and trained together. What is required in order to simulate age of acquisition effects are training regimes in which some items (the "early acquired" ones) are included in the training from the beginning, but others ("late acquired") are held back and only introduced after the network has undergone a substantial amount of training on the early set. Note that we are not proposing the replacement of the early acquired set by the late acquired set-a situation that may lead to "catastrophic interference" (McCloskey \& Cohen, 1989; Ratcliff, 1990)-but rather the gradual expansion of the training set in a manner comparable to the gradual expansion of the human vocabulary.

Unsupervised neural networks have been developed which "self-organize" on the basis of similarities and differences between items in the training set (Kohonen, 1984, 1990). Morrison (1993) showed that under certain circumstances, items introduced early in the training regime may come to occupy a larger amount of the network than do items introduced later, even after substantial amounts of additional training. We suggest that such self-organizing networks may offer a plausible model of how the various mental lexicons self-organize when gradually acquiring their vocabularies.

If early acquired words are distributed over more neurons than later acquired words, the total amount of activation induced by early and late acquired words may differ and create the basis for a difference in lexical decision speed if, as proposed in some recent theories, lexical decisions are based on the total amount of energy in the lexical system that is generated by that stimulus (e.g., Borowsky \& Masson, 1996; Plaut, in press; Rueckl, 1995). The notion that early acquired words are distributed over more neurons than late acquired words are might also explain why patients with some forms of neuropsychological impairments of word recognition and production may show better retention of early than of late acquired vocabulary (Hirsh \& Ellis, 1994; Hirsh \& Funnell, 1995).

\section{REFERENCES}

Balota, D. A., \& Chumbley, J. I. (1984). Are lexical decisions a good measure of lexical access? The role of word frequency in the neglected decision stage. Journal of Experimental Psychology: Human Perception \& Performance, 10, 340-357.

Barry, C., Morrison, C. M., \& Ellis, A. W. (1997). Naming the Snodgrass and Vanderwart pictures: Effects of age of acquisition, frequency and name agreement. Quarterly Journal of Experimental Psychol$0 g i, 50 \mathrm{~A}, 560-585$

Blosfeld, M. E., \& BRADLEY, D. C. (1981). Visual and auditory word recognition: Effects of frequency and syllabicity. Paper presented at the third Australian Language and Speech conference, Melbourne.

BOROWSKY. R. \& MASSON, M. E. J. (1996). Semantic ambiguity effects in word identification. Journal of Experimental Psychology: Learning, Memory, \& Cognition, 22, 63-85.

BroadBent, D. E. (1967). Word frequency effect and response bias. Psychological Review, 74, 1-15.

Brown, G. D. A., \& WATSON, F. L. (1987). First in, first out: Word learning age and spoken word frequency as predictors of word familiarity and word naming latency. Memory \& Cognition, 15, 208-216.

BUTLER, B., \& HAINS, S. (1979). Individual differences in word recognition latency. Memory \& Cognition, 7, 68-76.

Carroll, J. B., \& White, M. N. (1973a). Age of acquisition norms for 220 picturable nouns. Journal of Verbal Learning \& Verbal Behavior, $12,563-576$

Carroll, J. B., \& White, M. N. (1973b). Word frequency and age-ofacquisition as determiners of picture-naming latency. Quarterly Journal of Experimental Psychology, 25, 85-95.

CENTRE For LeXICAL INFORMATION (1993). The CELEX lexical database. Nijmegen: Author.

CirRin, F. M. (1984). Lexical search speed in children and adults. Journal of Experimental Child Psychology, 37, 158-175.

Coltheart, M., Davelaar, E., Jonasson, J. T., \& Besner, D. (1977). Access to the internal lexicon. In S. Dornic (Ed.), Attention and performance VI (pp. 535-555). New York: Academic Press.

COlThearT, V., \& WinOGRaD, E. (1986). Word imagery but not age of acquisition affects episodic memory. Memory \& Cognition, 14, 174-180

Connine, C. M., Mullenix, J., Shernoff, E., \& Yelen, J. (1990). Word familiarity and frequency in visual and auditory word recognition. Journal of Experimental Psychology: Learning, Memory, \& Cognition, 16, 1084-1096.

DupoIX, E., \& MEHLER, J. (1990). Monitoring the lexicon with normal and compressed speech: Frequency effects and the prelexical code. Journal of Memory \& Language, 29, 316-335.

Francis, W. N., \& KuČERA, H. (1982). Frequency analysis of English usage. Boston: Houghton-Mifflin.

GernSBaCher, M. A. (1984). Resolving 20 years of inconsistent interactions between lexical familiarity and orthography, concreteness and polysemy. Journal of Experimental Psychology: General, 113, 256-281

GuLHOOLY, K. J., \& GilhoоLy, M. L. (1979). Age-of-acquisition effects in lexical and episodic memory tasks. Memory \& Cognition, 7, 214-223.

Gil.hoOLY, K. J., \& Gilhooly, M. L. (1980). The validity of age-ofacquisition ratings. British Journal of Psychology, 71, 105-110.

GILHOOLY, K. J., \& LoGIE, R. H. (1980). Age-of-acquisition, imagery, concreteness, familiarity, and ambiguity measures for 1,944 words. Behavior Research Methods \& Instrumentation, 12, 395-427.

GILHOOLY, K. J., \& LoGIE, R. H. (1981). Word age-of-acquisition, reading latencies and auditory recognition. Current Psychological Research, 1, 251-262.

Gilhooly, K. J., \& Watson, F. L. (1981). Word age-of-acquisition effects: A review. Current Psychological Research, 1, 269-286.

Hirsh, K. W., \& Ellis, A. W. (1994). Age of acquisition and aphasia: A case study. Cognitive Neuropsychology, 11, 435-458.

Hirsh, K. W., \& FunNell, E. (1995). Those old, familiar things: Age of acquisition, familiarity and lexical access in progressive aphasia. Journal of Neurolinguistics, 9, 23-32.

HOWES, D. W. (1957). On the relationship between intelligibility and the frequency of occurrence of English words. Journal of the Acoustical Society of America, 29, 296-305.

JesCHENIAK, J. D., \& LEVELT, W. J. M. (1994). Word frequency effects in speech production: Retrieval of syntactic information and of phonological form. Journal of Experimental Psychology: Learning, Memory, \& Cognition, 20, 824-843.

KOHONEN, T. (1984). Self-organization and associative memory. Berlin: Springer-Verlag

KOHONEN, T. (1990). The self-organizing map. Proceedings of the IEEE, 78, 1464-1480.

LUCE, P. A. (1986). Neighborhoods of words in the mental lexicon. Unpublished doctoral dissertation, Indiana University.

MARSLEN-WIL.SON, W. D. (1987), Functional parallelism in spoken word recognition. Cognition. 25, $71-102$. 
MCClelland, J. L., \& Rumelhart, D. E. (1981). An interactive activation model of context effects in letter perception: Part 1. An account of basic findings. Psychological Review, 88, 375-407.

McCloskey, M., \& CoHeN, N. J. (1989). Catastrophic interference in connectionist networks: The sequential learning problem. In G. H. Bower (Ed.), The psychology of learning and motivation (Vol. 24, pp. 109-164). New York: Academic Press.

McCusker, L. X., Hillinger, M. L., \& Bias, R. G. (1981). Phonological recoding and reading. Psychological Bulletin, 89, 217-245.

MONSELL, S. (1991). The nature and locus of word frequency effects in reading. In D. Besner \& G. W. Humphreys (Eds.), Basic processes in reading: Visual word recognition (pp. 148-197). Hillsdale, $\mathrm{NJ}$ : Erlbaum.

Monsell, S., Doyle, M. C.. \& Haggard, P. N. (1989). Effects of frequency on visual word recognition tasks: Where are they? Journal of Experimental Psychology: General, 118, 43-71

MORRISON, C. M. (1993). Loci and roles of word age of acquisition and word frequency in lexical processing. Unpublished DPhil thesis, Unjversity of York.

Morrison, C. M., Chappell, T. D., \& Ellis, A. W. (1997). Age of acquisition norms for a large set of object names and their relation to adult estimates and other variables. Quarterly Journal of Experimental Psychology, 50A, 528-559.

Morrison, C. M., \& ElLIS, A. W. (1995). The roles of word frequency and age of acquisition in word naming and lexical decision. Journal of Experimental Psychology: Learning, Memory; \& Cognition, 21, 116-133.

Morrison, C. M., Ellis, A. W., \& Quinlan, P. T. (1992). Age of acquisition, not word frequency, affects object naming, not object recognition. Memory \& Cognition, 20, 705-714.

MORTON, J. (1969). Interaction of information in word recognition. Psychological Review, 76, 165-178.

MorTon, J. (1979). Facilitation in word recognition: Experiments causing change in the logogen model. In P. A. Kolers, M. Wrolstad, \& H. Bouma (Eds.), Processing of visible language (Vol. 1, pp. 259-268). New York: Plenum.

MORTON, J. (1982). Disintegrating the lexicon: An information processing approach. In J. Mehler, S. Franck, E. C. T. Walker, \& M. Garrett (Eds.), Perspectives on mental representations (pp. 89-109). Hillsdale, $\mathrm{NJ}$ : Erlbaum.

NagY, W. E., Anderson, R. C., Schommer, M., Scott, J. A., \& StallMAN, A. C. (1989). Morphological families in the internal lexicon. Reading Research Quarterly, 24, 262-282.

OlDFIELD, R. C., \& WINGFIELD, A. (1965). Response latencies in naming objects. Quarterly Journal of Experimental Psychology, 4, 272-281.

Paivio, A., Yuille, J. D., \& Madigan, S. A. (1968). Concreteness, imagery, and meaningfulness values for 925 nouns. Journal of Experimental Psychology Monographs, 76 (1, Pt. 2), 1-25.
Plaut, D. C. (in press). Structure and function in the lexical system: Insights from distributed models of word reading and lexical decision. Language \& Cognitive Processes.

QUINLAN, P. T. (1992). The MRC psycholinguistic database. Oxford: Oxford University Press.

RATCLIFF, R. (1990). Connectionist models of recognition memory: Constraints imposed by learning and forgetting functions. Psychological Review, 97, 285-308.

RuBin, D. C. (1980). 51 properties of 125 words: A unit analysis of verbal behavior. Journal of Verbal Learning \& Verbal Behavior, 19, 736-755.

RUECKL, J. G. (1995). Ambiguity and connectionist networks: Still settling into a solution - comment on Joordens and Besner (1994). Journal of Experimental Psychology: Learning. Memory, \& Cognition, 21, 505-508.

Sears, C. R., Hino, Y., \& Lupker, S. J. (1995). Neighborhood size and neighborhood frequency effects in word recognition. Journal of Experimental Psychology: Human Perception \& Performance, 21, 870-900.

Seidenberg, M. S., \& McClelland, J. L. (1989). A distributed, developmental model of word recognition and naming. Psychological Review, 96, 523-568.

TYLER, L. K. (1984). The structure of the initial cohort: Evidence from gating. Perception \& Psychophysics, 36, 417-427.

WHALEY, C. P. (1978). Word-nonword classification time. Journal of Verbal Learning \& Verbal Behavior, 17, 143-154.

YounG, A. W., \& ElLIS, H. D. (1980). Ear asymmetry for the perception of monaurally presented words accompanied by binaural white noise. Neuropsychologia, 18, 107-110.

\section{NOTE}

1. An anonymous reviewer queried the possible contribution of word familiarity (cf. Gernsbacher, 1984) to the age of acquisition effects observed in Experiments 2 and 4 . We have, therefore, included in the Appendices familiarity values taken from the Oxford Psycholinguistic Database (Quinlan, 1992). Familiarity was not controlled in the word sets used, and it is clear from Appendices $A$ and $B$ that the highfrequency and the early acquired word sets are rated as being more familiar than are the low-frequency and late acquired sets [frequency, $t(30)=6.48, p<.01$; age of acquisition, $t(32)=4.84, p<.01]$. However, if the familiarity of stimuli played a major role in determining lexical decision speed, we might have expected to obtain an apparent effect of frequency in Experiment 1, yet we did not. We would also note Brown and Watson's (1987) observation that familiarity ratings are predicted better by age of acquisition than by any of the available frequency measures. In our word sets, familiarity is more highly correlated with age of acquisition $(r=.62)$ than with either written frequency $(r=.45)$ or spoken frequency $(r=.42)$. 
APPENDIX A

High- and Low-Frequency Word Sets, Matched for Age of Acquisition (as Used in Experiments 1 and 3)

\begin{tabular}{|c|c|c|c|c|c|c|c|c|c|c|c|c|c|c|c|}
\hline $\begin{array}{l}\text { Higher } \\
\text { Frequency }\end{array}$ & $F \& K$ & SF & I & A & $\mathrm{N}$ & Fam & RT & $\begin{array}{c}\text { Lower } \\
\text { Frequency }\end{array}$ & $F \& K$ & $\mathrm{SF}$ & I & A & $\mathrm{N}$ & Fam & RT \\
\hline arm & 94 & 22 & 5.93 & 1.92 & 9 & 6.08 & 494 & $\operatorname{arch}$ & 13 & 2 & 5.57 & 3.67 & 1 & 4.83 & 525 \\
\hline back & 967 & 1,006 & 4.83 & 2.25 & 17 & 5.87 & 514 & bag & 42 & 26 & 5.70 & 2.17 & 28 & 6.34 & 524 \\
\hline bed & 127 & 78 & 6.35 & 1.69 & 18 & 6.36 & 614 & bet & 20 & 7 & 4.53 & 3.64 & 23 & 5.27 & 622 \\
\hline base & 91 & 39 & 4.36 & 3.69 & 17 & 5.20 & 710 & babe & 10 & 0 & 5.62 & 3.03 & 10 & 3.70 & 842 \\
\hline boat & 69 & 50 & 6.31 & 1.90 & 16 & 5.84 & 560 & bat & 13 & 5 & 5.86 & 2.75 & 30 & 5.14 & 585 \\
\hline birth & 66 & 25 & 5.32 & 3.28 & 6 & 5.27 & 632 & bird & 31 & 19 & 6.14 & 2.06 & 10 & 5.92 & 442 \\
\hline blood & 121 & 33 & 6.20 & 2.53 & 5 & 5.71 & 480 & blush & 2 & 0 & 5.51 & 3.78 & 4 & 5.35 & 637 \\
\hline book & 193 & 524 & 5.91 & 2.14 & 17 & 6.43 & 499 & bush & 14 & 14 & 5.49 & 2.56 & 15 & 5.32 & 569 \\
\hline bus & 64 & 47 & 6.75 & 2.20 & 13 & & 687 & bud & 9 & 9 & 5.08 & 3.31 & 20 & 4.65 & 741 \\
\hline coat & 43 & 13 & 5.72 & 1.97 & 14 & 6.10 & 574 & cone & 13 & 0 & 5.59 & 2.75 & 26 & 5.06 & 681 \\
\hline $\operatorname{dog}$ & 75 & 39 & 6.36 & 1.69 & 23 & 5.98 & 523 & dot & 13 & 20 & 5.56 & 2.19 & 25 & 5.24 & 625 \\
\hline flesh & 52 & 2 & 5.67 & 4.11 & 4 & 4.83 & 523 & flash & 21 & 2 & 5.28 & 3.14 & 7 & 5.09 & 527 \\
\hline grade & 35 & 35 & 3.97 & 4.17 & 11 & 5.33 & 682 & grape & 3 & 0 & 5.91 & 2.97 & 15 & 5.32 & 516 \\
\hline green & 116 & 45 & 6.09 & 2.25 & 6 & 5.83 & 573 & greed & 3 & 2 & 4.20 & 2.94 & 6 & 4.94 & 537 \\
\hline half & 275 & 360 & 4.58 & 2.67 & 9 & 6.10 & 660 & harm & 25 & 22 & 3.62 & 3.06 & 13 & 5.36 & 631 \\
\hline head & 424 & 62 & 5.93 & 1.81 & 13 & 6.11 & 515 & hedge & 2 & 1 & 5.83 & 3.06 & 5 & 4.87 & 571 \\
\hline heart & 173 & 59 & 6.17 & 2.81 & 2 & 5.78 & 529 & harp & 1 & 1 & 6.21 & 4.00 & 10 & 4.30 & 558 \\
\hline home & 547 & 365 & 5.99 & 2.33 & 19 & 6.26 & 642 & hose & 9 & 1 & 5.72 & 3.14 & 14 & 4.49 & 575 \\
\hline line & 298 & 174 & 4.91 & 2.75 & 31 & 5.91 & 570 & lime & 13 & 3 & 5.63 & 3.78 & 19 & 4.47 & 725 \\
\hline love & 232 & 113 & 5.69 & 3.03 & 20 & 6.19 & 586 & luck & 47 & 32 & 3.99 & 2.92 & 15 & 5.87 & 499 \\
\hline note & 127 & 41 & 5.03 & 2.92 & 16 & 5.94 & 542 & nose & 60 & 32 & 6.05 & 2.06 & 13 & 5.84 & 474 \\
\hline part & 500 & 577 & 3.40 & 3.14 & 18 & 5.79 & 617 & park & 94 & 31 & 5.73 & 2.19 & 21 & 5.71 & 570 \\
\hline rain & 70 & 24 & 6.18 & 2.11 & 20 & 6.04 & 598 & rake & 11 & 11 & 5.50 & 3.36 & 20 & 4.76 & 665 \\
\hline rate & 209 & 165 & 3.11 & 4.56 & 26 & 5.27 & 717 & raid & 10 & 2 & 4.76 & 3.91 & 9 & 4.87 & 717 \\
\hline road & 197 & 197 & 6.09 & 2.06 & 10 & 6.04 & 519 & rope & 15 & 1 & 5.96 & 2.81 & 21 & 5.39 & 500 \\
\hline shape & 85 & 61 & 4.71 & 3.03 & 10 & 5.75 & 453 & shame & 21 & 21 & 4.19 & 3.67 & 7 & 5.34 & 623 \\
\hline sheet & 45 & 50 & 5.94 & 2.51 & 8 & 6.16 & 601 & sheep & 20 & 7 & 5.96 & 1.90 & 9 & 5.07 & 445 \\
\hline trip & 81 & 13 & 5.20 & 3.14 & 6 & 5.59 & 511 & trick & 15 & 6 & 4.59 & 3.08 & 7 & 5.31 & 503 \\
\hline type & 200 & 171 & 3.95 & 3.83 & 8 & 5.67 & 609 & tide & 11 & 7 & 5.30 & 3.31 & 17 & 5,04 & 539 \\
\hline win & 55 & 10 & 4.54 & 2.69 & 17 & 5.82 & 739 & wick & 4 & 8 & 5.35 & 3.53 & 11 & 4.38 & 708 \\
\hline wood & 55 & 33 & 5.77 & 2.69 & 12 & 5.74 & 575 & wool & 10 & 4 & 5.87 & 2.47 & 9 & 5.40 & 608 \\
\hline wrong & 129 & 331 & 3.44 & 2.44 & 3 & 6.00 & 612 & rod & 18 & 18 & 5.49 & 2.78 & 21 & 5.04 & 450 \\
\hline$M$ & 181.7 & 148.9 & 5.33 & 2.70 & 13 & 5.84 & & & 18.53 & 9.8 & 5.37 & 3.00 & 14.4 & 5.12 & \\
\hline$S D$ & 193.5 & 216.8 & 0.98 & 0.75 & 6.9 & .36 & & & 19.05 & 10.4 & 0.66 & 0.59 & 7.5 & 5.3 & \\
\hline
\end{tabular}

Note-F\&K, Francis and Kučera (1982) written word frequency; SF, CELEX spoken word frequency; I, imageability; A, age of acquisition; N, orthographic neighbors; Fam, familiarity; RT, reaction time (in milliseconds). 
APPENDIX B

Early and Late Age of Acquisition Word Sets, Matched for Age of Acquisition (as Used in Experiments 2 and 4 )

\begin{tabular}{|c|c|c|c|c|c|c|c|c|c|c|c|c|c|c|c|}
\hline $\begin{array}{c}\text { Earlier Age of } \\
\text { Acquisition }\end{array}$ & F\&K & SF & I & A & $\mathrm{N}$ & Fam & RT & $\begin{array}{c}\text { Later Age of } \\
\text { Acquisition }\end{array}$ & $F \& K$ & SF & I & A & $\mathrm{N}$ & Fam & RT \\
\hline arm & 94 & 22 & 5.93 & 1.92 & 9 & 6.08 & 520 & arch & 13 & 2 & 5.57 & 3.67 & 1 & 4.83 & 596 \\
\hline bird & 31 & 19 & 6.14 & 2.06 & 10 & 5.92 & 490 & birth & 66 & 25 & 5.32 & 3.28 & 6 & 5.27 & 670 \\
\hline brick & 4 & 13 & 5.74 & 2.61 & 9 & 5.29 & 485 & brim & 4 & 0 & 5.10 & 3.94 & 11 & 4.30 & 678 \\
\hline cake & 13 & 5 & 6.24 & 2.14 & 21 & 5.94 & 583 & cage & 9 & 3 & 5.85 & 3.00 & 17 & 4.87 & 495 \\
\hline cat & 23 & 9 & 6.17 & 1.50 & 29 & 5.82 & 512 & cap & 17 & 7 & 6.40 & 2.90 & 27 & 4.29 & 495 \\
\hline cheese & 9 & 5 & 5.92 & 2.11 & 2 & 5.88 & 505 & cheek & 20 & 2 & 5.61 & 2.67 & 5 & 5.33 & 513 \\
\hline coat & 43 & 13 & 5.72 & 1.97 & 14 & 6.10 & 555 & coach & 24 & 19 & 5.60 & 3.14 & 6 & 5.09 & 596 \\
\hline dot & 13 & 20 & 5.56 & 2.19 & 25 & 5.24 & 632 & dock & 8 & 2 & 5.59 & 3.67 & 13 & 4.83 & 597 \\
\hline drum & 53 & 5 & 5.99 & 2.00 & 7 & 5.06 & 671 & drug & 24 & 10 & 5.64 & 4.64 & 5 & 5.39 & 487 \\
\hline foot & 70 & 72 & 5.97 & 1.50 & 14 & 5.83 & 521 & fat & 60 & 14 & 5.74 & 2.36 & 25 & 6.09 & 525 \\
\hline fork & 14 & 5 & 5.98 & 2.25 & 10 & 5.84 & 532 & fawn & 1 & 0 & 5.65 & 3.94 & 10 & 4.33 & 735 \\
\hline flash & 21 & 2 & 5.28 & 3.14 & 7 & 5.09 & 565 & flesh & 52 & 2 & 5.67 & 4.11 & 4 & 4.83 & 547 \\
\hline greed & 3 & 2 & 4.20 & 2.94 & 6 & 4.94 & 591 & grief & 10 & 4 & 4.80 & 4.50 & 2 & 5.05 & 648 \\
\hline groan & 1 & 29 & 5.06 & 3.42 & 3 & 5.08 & 604 & grove & 14 & 14 & 4.70 & 4.83 & 8 & 3.74 & 683 \\
\hline harm & 25 & 22 & 3.62 & 3.06 & 13 & 5.36 & 604 & harp & 1 & 1 & 6.21 & 4.00 & 10 & 4.30 & 555 \\
\hline hat & 56 & 26 & 5.62 & 2.10 & 29 & 5.80 & 489 & heat & 97 & 2 & 5.07 & 2.78 & 18 & 5.80 & 550 \\
\hline hide & 2 & 1 & 4.30 & 2.56 & 16 & 5.15 & 562 & hive & 2 & 18 & 5.54 & 3.19 & 16 & 3.86 & 614 \\
\hline germ & 3 & 0 & 4.42 & 3.19 & 8 & 5.23 & 661 & jerk & 2 & 1 & 4.79 & 4.00 & 7 & 4.52 & 559 \\
\hline leaf & 12 & 6 & 6.08 & 2.05 & 12 & 5.56 & 542 & leak & 2 & 3 & 5.45 & 3.36 & 14 & 5.14 & 615 \\
\hline line & 298 & 174 & 4.91 & 2.75 & 31 & 5.91 & 583 & lime & 13 & 3 & 5.63 & 3.78 & 19 & 4.47 & 740 \\
\hline look & 399 & 406 & 3.95 & 2.25 & 15 & 6.07 & 540 & love & 232 & 113 & 5.69 & 3.03 & 20 & 6.19 & 581 \\
\hline nose & 60 & 32 & 6.05 & 2.06 & 13 & 5.84 & 529 & note & 127 & 41 & 5.03 & 2.92 & 16 & 5.94 & 559 \\
\hline park & 94 & 31 & 5.73 & 2.19 & 21 & 5.71 & 676 & part & 500 & 577 & 3.40 & 3.14 & 18 & 5.79 & 653 \\
\hline pig & 8 & 4 & 6.33 & 2.33 & 21 & 5.09 & 507 & pit & 14 & 9 & 5.89 & 3.14 & 25 & 4.93 & 730 \\
\hline pot & 28 & 9 & 5.98 & 2.17 & 26 & 5.77 & 619 & port & 21 & 9 & 5.46 & 3.72 & 15 & 4.81 & 560 \\
\hline raid & 10 & 2 & 4.76 & 3.91 & 9 & 4.87 & 683 & rate & 209 & 165 & 3.11 & 4.56 & 26 & 5.27 & 742 \\
\hline road & 197 & 197 & 6.09 & 2.06 & 10 & 6.04 & 571 & rope & 15 & 1 & 5.96 & 2.81 & 21 & 5.39 & 578 \\
\hline rug & 13 & 2 & 5.91 & 2.33 & 19 & 5.57 & 500 & rung & 3 & 2 & 4.80 & 4.14 & 10 & 4.23 & 670 \\
\hline sheep & 19 & 7 & 5.96 & 1.90 & 9 & 5.07 & 486 & sheet & 45 & 50 & 5.94 & 2.51 & 8 & 6.16 & 608 \\
\hline slide & 12 & 21 & 4.83 & 2.30 & 9 & 5.29 & 507 & slice & 13 & 2 & 5.07 & 2.92 & 6 & 5.40 & 578 \\
\hline spell & 19 & 16 & 4.29 & 2.92 & 9 & 5.25 & 591 & speck & 7 & 2 & 5.03 & 3.53 & 6 & 4.77 & 576 \\
\hline tap & 18 & 10 & 5.41 & 2.22 & 25 & 5.67 & 573 & tack & 4 & 3 & 5.46 & 3.83 & 16 & 4.63 & 692 \\
\hline win & 55 & 10 & 4.54 & 2.69 & 17 & 5.82 & 709 & wick & 4 & 8 & 5.35 & 3.53 & 11 & 4.38 & 728 \\
\hline$M$ & 52.1 & 36.3 & 5.41 & 2.39 & 14.0 & 5.55 & & & 49.5 & 33.8 & 5.34 & 3.50 & 12.8 & 4.98 & \\
\hline$S D$ & 86.6 & 79.6 & 0.77 & 0.54 & 7.8 & 0.38 & & & 98.2 & 103 & 0.68 & 0.62 & 7.27 & 0.75 & \\
\hline
\end{tabular}

Note-F\&K, Francis and Kučera * (1982) written word frequency; SF, CELEX spoken word frequency; I, imageability; A, age of acquisition; N, orthographic neighbors; Fam, familiarity; RT, reaction time (in milliseconds). 